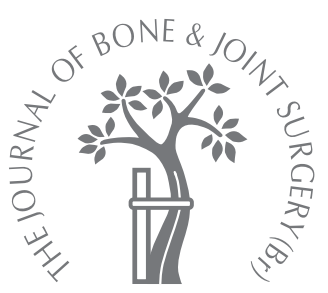

T. O. Hammer, R. Wieling, J. M. Green, N. P. Südkamp, E. Schneider, C. A. Müller

From AO Research Institute, Davos, Switzerland

I. O. Hammer, MD, Trauma and Orthopaedic Surgeon

N. P. Südkamp, MD

Professor, Trauma and

Orthopaedic Surgeon

Department of Orthopaedics

and Trauma Surgery

Hugstetterstrasse 55, D-79106

Freiburg, Germany.

n. Wieling, MBA, Manager Medical Projects

Icotec ag, CH-9450, Altstäten, Switzerland

I. M. Green, BS, Director 1302 Wrights Lane, West Chester, Pennsylvania 19380, USA.

E. Schneider, MSc, Professor and Director

AO Research Institute,

Clavadelerstrasse 8, 7270

Davos, Switzerland.

= C. A. Müller, MD, PhD, Trauma and Orthopaedic

Surgeon

Department of Orthopaedic and

Trauma Surgery

Klinikum Karlsruhe,

Moltkestrasse 90, D 46733,

Karlsruhe, Germany.

Correspondence should be sent to $\mathrm{Dr}$ T. O. Hammer; e-mail: thorsten.hammer@uniklinikfreiburg.de

(C)2007 British Editorial Society of Bone and Joint Surgery doi:10.1302/0301-620X.89B11. $18994 \$ 2.00$

$J$ Bone Joint Surg [Br] 2007;89-B:1534-8.

Received 5 December 2006,

Accepted after revision 19 July 2007

\title{
Effect of re-implanted particles from intramedullary reaming on mechanical properties and callus formation
}

\author{
A LABORATORY STUDY
}

This study investigated the quality and quantity of healing of a bone defect following intramedullary reaming undertaken by two fundamentally different systems; conventional, using non-irrigated, multiple passes; or suction/irrigation, using one pass. The result of a measured re-implantation of the product of reaming was examined in one additional group. We used 24 Swiss mountain sheep with a mean tibial medullary canal diameter between $8 \mathrm{~mm}$ and $9 \mathrm{~mm}$. An $8 \mathrm{~mm}$ 'napkin ring' defect was created at the mid-diaphysis. The wound was either surgically closed or occluded. The medullary cavity was then reamed to $11 \mathrm{~mm}$. The Reamer/Irrigator/Aspirator (RIA) System was used for the reaming procedure in groups $A$ (RIA and autofilling) and $B$ (RIA, collected reamings filled up), whereas reaming in group $C$ (Synream and autofilling) was performed with the Synream System. The defect was allowed to auto-fill with reamings in groups $A$ and $C$, but in group $B$, the defect was surgically filled with collected reamings. The tibia was then stabilised with a solid locking Unreamed Humerus Nail (UHN), $9.5 \mathrm{~mm}$ in diameter. The animals were killed after six weeks. After the implants were removed, measurements were taken to assess the stiffness, strength and callus formation at the site of the defect.

There was no significant difference between healing after conventional reaming or suction/irrigation reaming. A significant improvement in the quality of the callus was demonstrated by surgically placing captured reamings into the defect using a graft harvesting system attached to the aspirator device. This was confirmed by biomechanical testing of stiffness and strength. This study suggests it could be beneficial to fill cortical defects with reaming particles in clinical practice, if feasible.

Intramedullary fixation of long bones has been attempted since ancient times but until the focused approach of Küntscher, ${ }^{1}$ combined with the necessity for the management of casualties in World War II, there was little progress with this surgical method. His work led many to awareness about both the possibility and the practicality of intramedullary nailing. Over the past 60 years, this method has been expanded, modified and applied with innumerable improvements. A notable advancement occurred when reaming was introduced, enabling the implantation of stronger, larger-diameter nails that gave greater stability. However, a persistent problem remains with this procedure, which was identified by Küntscher ${ }^{1}$ himself. Adverse events sometimes occurred, probably as a result of the introduction of marrow content into the vascular system. In order to reduce this possibility, he recommended a delay in surgery with the limb maintained in a distractor until the period of risk had passed.
Because displaced medullary content was thought to initiate those pathological consequences, early efforts investigated the possibility of removing or reducing this factor. Danckwardt-Lillieström et $\mathrm{al}^{2}$ showed that by combining reaming with suction and irrigation, local damage to the bone could be prevented, and, more importantly, the systemic outcome of the animal subjects improved. This work was continued by Stürmer, ${ }^{3}$ who demonstrated the possibility of undertaking negative-pressure reaming in a larger animal model.

Suction irrigation reaming remained only a laboratory technique because of difficulty in developing suitable clinical devices, but the need for reducing intramedullary pressure remained a goal. With the aim of achieving this, surgical treatment moved towards the use of high-strength, small-diameter nails which could be implanted without reaming but were sufficiently strong to sustain patient loading. This non-reamed technique reduced the cre- 


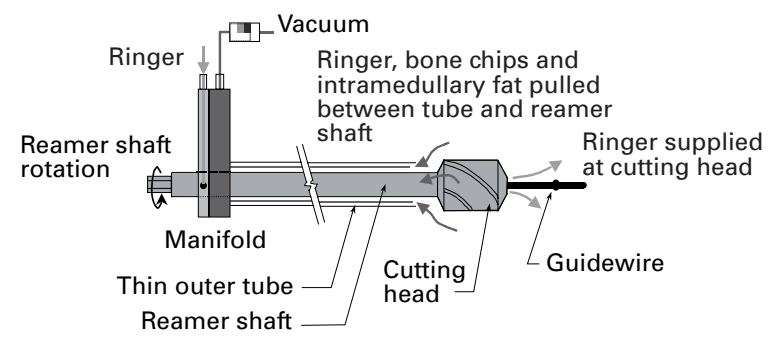

Fig. 1

Diagram of the Reamer Irrigator Aspirator.
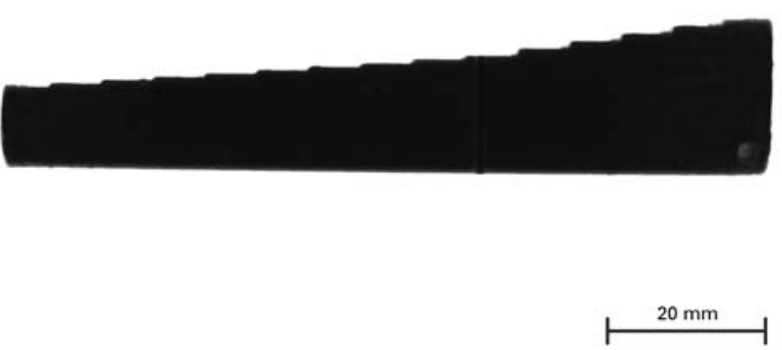

Fig. 2

Diagram of aluminium step wedge for calibration of areas of callus.

ation of an inflammatory product, ${ }^{4,5}$ but did not avoid the increased pressure and embolic phenomena, ${ }^{6,7}$ nor did it abolish the adverse consequences of intramedullary fixation. ${ }^{8}$ Moreover, unreamed nails are associated with lower rates of union than traditionally reamed nails. ${ }^{9}$

With the introduction of a suction/irrigation reaming system, the Reamer/Irrigator/Aspirator (RIA), (Synthes, West Chester, Pennsylvania), this former laboratory method has become a surgical reality. This paper describes an experiment to determine the effect of this reaming method on the healing of bone defects as measured by strength, stiffness and callus formation.

\section{Materials and Methods}

The study was approved by the canton of Graubünden, Switzerland. We used 24 adult Swiss mountain sheep with a mean weight of $62 \mathrm{~kg}$ (54 to 68). The animals were divided into three groups of eight sheep to ensure an equal distribution in the diameter of the medullary cavity of the left tibia. Reaming was performed in groups A (RIA and autofilling) and B (RIA and filling with collected reamings) using the RIA system. This design consists of a nitinol drive shaft that turns a cutting head and simultaneously conveys irrigation to cool the cutting interface and to flush away reamed material. The shaft is contained within an outer plastic tube, the aspiration sleeve whose diameter is slightly smaller than the smallest reamer head that can be affixed to the drive shaft. The cuttings from, and contents of, the medullary cavity are aspirated completely as slurry, transported by the irrigation fluid drawn through the space between the reamer shaft and the aspirator sleeve. The particles may be collected using a mesh screen or trap, as was done for this study (Fig. 1). The Synream (Synthes) is a newer, conventional, reaming system that also uses a smalldiameter nitinol drive shaft but has reamer heads whose diameter is increased sequentially in increments of $0.5 \mathrm{~mm}$. These heads are not irrigated.

A stabilising external fixator (Synthes) with a single proximal and distal Schanz screw (Synthes) was temporarily applied to the left tibia. An $8 \mathrm{~mm}$ 'napkin ring' defect was created at the mid-diaphysis (Fig. 2), and the wound was closed in the eight sheep in groups A and C (Synream Reamer and autofilled defect) to reconstruct a soft-tissue envelope. An occlusive dressing was applied to animals in group B to maintain a barrier to ambient air, which could reduce the suction performance of the RIA. Reaming to $11 \mathrm{~mm}$ was performed in a single step in groups A and B prepared by RIA. In group C, using the Synream System, the canal was reamed sequentially from $8.5 \mathrm{~mm}$ to $11 \mathrm{~mm}$ in $0.5 \mathrm{~mm}$ increments.

In groups $\mathrm{A}$ and $\mathrm{C}$, the defect was allowed to accumulate reamings by auto-fill. In group B, the RIA was passed as with group A but the reamings were captured, the barrier dressing removed and the reamed particles surgically implanted into the defect. The wound was then closed as in groups A and C. Finally, each bone was stabilised with a solid interlocked nail (Unreamed Humerus Nail (UHN), $9.5 \mathrm{~mm}$ diameter, $190 \mathrm{~mm}$ length; Synthes). Plain radiographs were taken in two planes post-operatively at two, four and six weeks. The aluminium step wedge was included on every radiograph (Fig. 2). The animals were killed after six weeks by slow intravenous administration of $20 \mathrm{ml}$ of vetarnacol.

The torsional strength and stiffness of the healing bony defect were measured in a hydraulic materials testing device (MTS Bionix 858; MTS Systems Corporation, Minneapolis, Minnesota) (Fig. 3). The embedded bone ends were fitted longitudinally into the grip head and fastened. The proximal end was twisted in relation to the distal end at a constantly increasing turning moment until the bone broke. The measured values were fed into the computer via a data recording system (Adwin Gold, Lorsch, Germany) and were analysed using Matlab 6.5 (The MathWorks Co., Natick, Massachussetts). The tibiae from the intact right side were tested in the same way.

The area of callus was measured interactively in both the mediolateral and anteroposterior (AP) projections immediately after operation and at two, four and six weeks, and cal- 


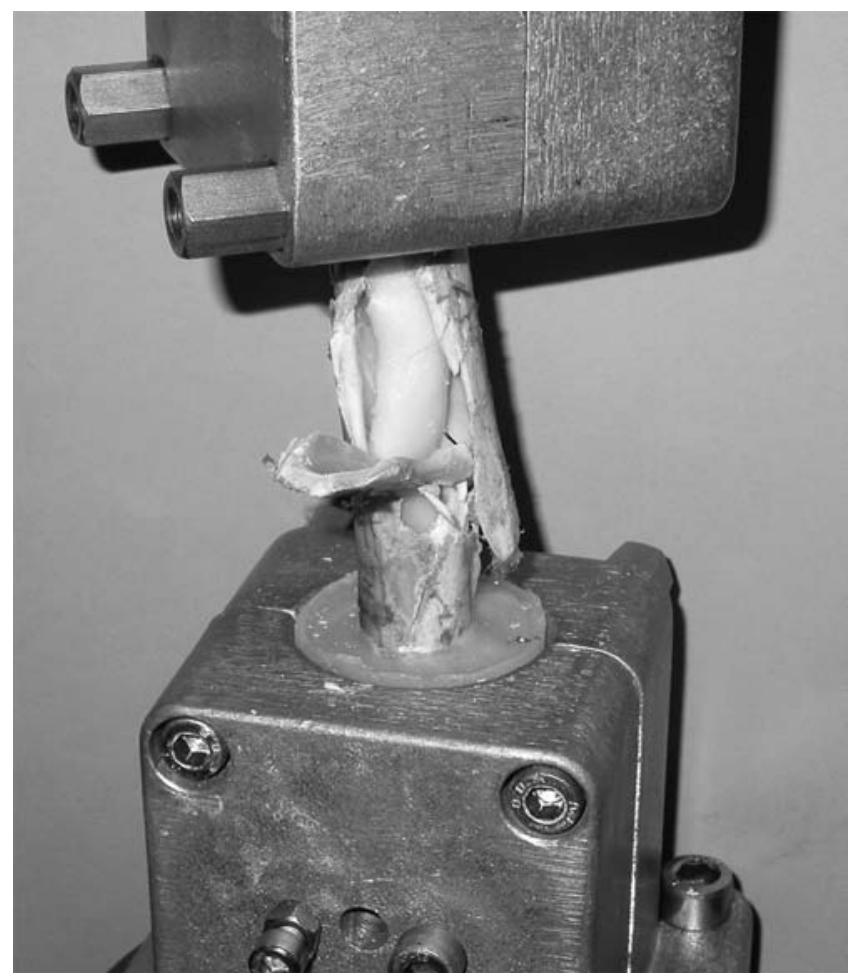

Fig. 3

Photograph of the materials testing device.

culated with reference to its scanning elements. The marked areas were exported as the number of pixels into an Excel table (Version 2000; Microsoft, Redmond, Washington). An aluminium wedge with 15 steps and a length of $97.5 \mathrm{~mm}$ was also measured on the image and its data likewise exported into an Excel table. With reference to the aluminium wedge, a calibration factor (f) was calculated and applied to convert the areas measured to $\mathrm{mm}^{2}$. For the purpose of group comparison, a Kolmogorov-Smirnov test was implemented first in order to test for normal distribution. If the result is non-significant, there is normal distribution of the data and parametric tests can be applied. If the result is significant, the distribution is not normal and non-parametric procedures must be used. A Kruskal-Wallis test to search for significant $(\mathrm{p}<0.05)$ differences between the groups was performed in both parametric and non parametric distributions. If the result was not significant, no global differences between the groups were expected and no further analyses were performed. A significant result indicates differences between the groups, and a Mann-Whitney $\mathrm{U}$ test can be carried out to identify the differences and to calculate their significance values.

\section{Results}

Stiffness. In group B, in which the debris from RIA was implanted into the defect surgically, a mean value of 1.21 $\mathrm{Nm} /{ }^{\circ}$ (SD 0.54) was achieved, whereas measurements in

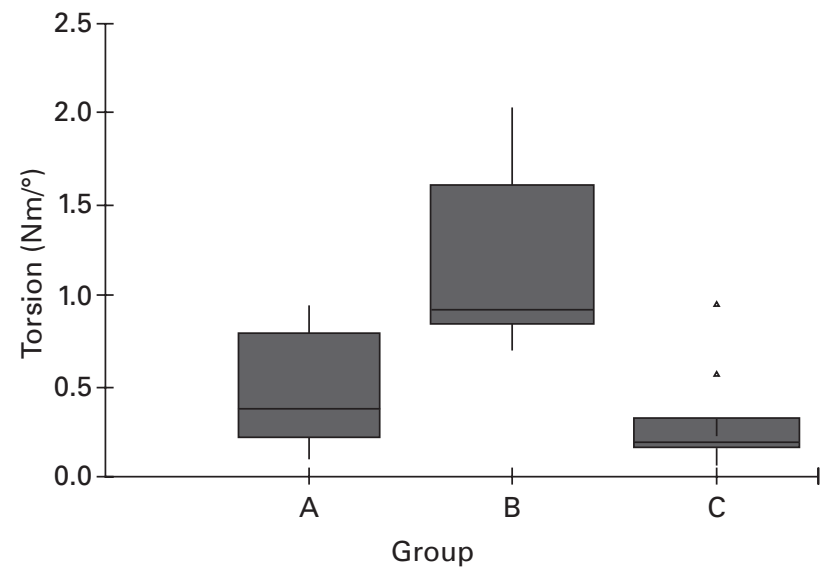

Fig. 4

Graph showing stiffness of the operated left tibiae, in groups A, B and C. Far values relate to outliers. Box plots indicate median values.

groups $\mathrm{A}$ and $\mathrm{C}$ only yielded mean values of $0.48 \mathrm{Nm} /{ }^{\circ}$ (SD 0.36 ) and $0.31 \mathrm{Nm} /{ }^{\circ}$ (SD 0.30), respectively. There was a significant difference in the stiffness of the left tibiae in group $\mathrm{B}$ and group A (Mann-Whitney U test, $\mathrm{p}=0.029$ ). A highly significant difference was found between group B (MannWhitney $\mathrm{U}$ test, $\mathrm{p}=0.002$ ) and group $\mathrm{C}$ (Fig. 4).

Torsional strength. In group B, a mean value of $14.09 \mathrm{Nm}$ (SD 4.74) was found, whereas measurements in groups $A$ and $C$ yielded mean values of $6.94 \mathrm{Nm}$ (SD 4.77) and 5.21 (SD 2.64), respectively. There was a significant difference in the torsional strength of the left tibiae in group $\mathrm{B}$ compared with group A (Mann-Whitney $U$ test, $p=0.029$ ). A highly significant difference was found between group B (Mann-Whitney U test, $\mathrm{p}=0.001$ ) and group C. In contrast, no significance was found between group A and group C (Mann-Whitney $\mathrm{U}$ test, $\mathrm{p}=0.491$ ).

Areas of callus. In contrast to mechanical testing, evaluation of the areas of callus after four weeks showed distinct differences in the mean values of groups A and B compared with group C. In group A, the mean area of callus was 1426.26 $\mathrm{mm}^{2}$ (SD 1135.06), and in group B it was $1042.54 \mathrm{~mm}^{2}$ (SD 476.79). In group C, the mean area was $405.60 \mathrm{~mm}^{2}$ (SD 463.32). There was significantly more callus after four weeks in group B than in group C (Mann-Whitney U test, $\mathrm{p}=$ 0.028). A significant difference between group $A$ and group $C$ was not achieved (Mann-Whitney U test, $p=0.081$ ). No significant difference was found between group $\mathrm{A}$ and group B (Mann-Whitney U test, $\mathrm{p}=0.755$ ) (Fig. 5).

\section{Discussion}

The intramedullary reamers, developed by Küntscher ${ }^{1}$ in the early 1950s present both well-known benefits and problems. They enable the surgeon to increase the intramedullary diameter, allowing the insertion of a larger and 


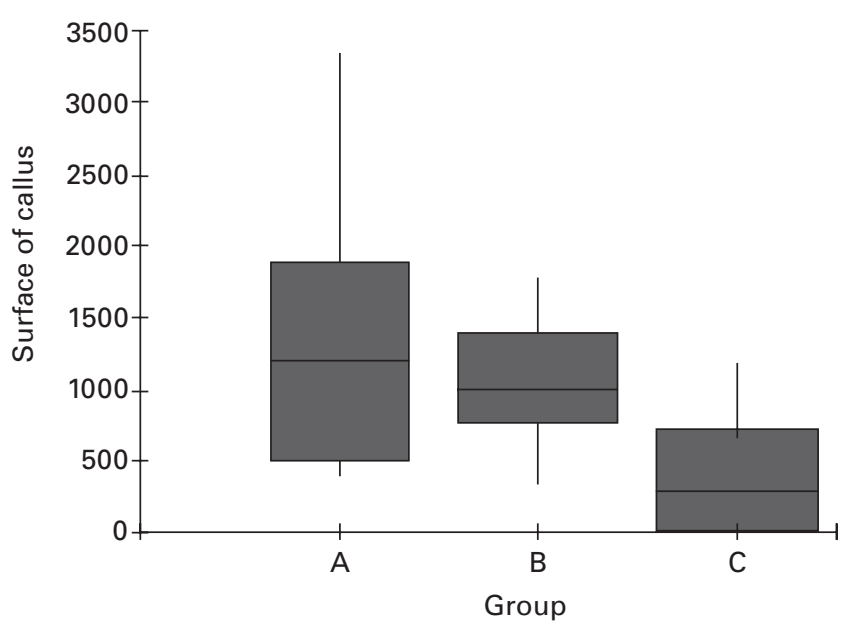

Fig. 5

Graph showing area of callus in week four, in groups A, B and C. Box plots indicate median values.

stronger nail which is more likely to survive the period needed for fracture healing. Their disadvantages, physiologically, are local injury to bone and potential systemic damage from the passage of cutting debris and intramedullary content into the vascular channels. ${ }^{10}$

Using a conventional reaming technique in a rabbit, Danckwardt-Lillieström et $\mathrm{al}^{2}$ found extrusion of marrow content through the haversian and Volkmann's channels into the extra-osseous drainage of the tibia. The process of reaming and infarction by fat caused disruption of the intracortical blood supply. They noted that in animals, where the fat was first removed using suction and irrigation, the blood supply was preserved, reperfusion occurred intracortically, and there were no deaths from fat emboli, whereas this occurred in $11 \%$ of the animals from whom the canal contents were not evacuated. They speculated that, in addition to acting as a mechanical block, "the decomposed fat may act as a toxic factor and prevent normal revascularisation". ${ }^{11}$

Stürmer ${ }^{12}$ investigated suction/irrigation reaming in sheep. Reaming was irrigated by the introduction of fluid distally through a cannulated guide wire and removed proximally through a suction port. The flow of irrigation in the intact bone served coincidentally to rinse and cool the reamer head at the same time as removing the debris. This technique helped preserve the viability of the cortical bone, and he noted that "a significant difference $(\mathrm{p}<0.05)$ emerged in favour of the group with irrigation: here $38.5 \%$ of the cortex remained vital compared to only $27.6 \%$ for conventional reaming techniques". ${ }^{12}$

Stürmer ${ }^{12}$ introduced the $\mathrm{Q}_{l e}$ formula, which defined the variables affecting the intramedullary pressure with reaming. According to this formula, decreasing viscosity and a differential pressure $(\mathrm{D} p)$, which directed flow out of the canal, were essential in avoiding the standard problems of reaming. He wrote: "Continuous irrigation of the medul- lary cavity during reaming may be the most effective means of pressure reduction. If it is combined with suction, negative pressure may even be produced." He also observed that "a potential disadvantage of the method is the loss of the reaming haematoma at the fracture site which may lead to a delay in callus formation".

The development of the RIA system makes suction/irrigation reaming an everyday clinical possibility, but raises questions that have practical relevance. What is the effect of the RIA on fracture healing? Because the reamings can be captured and replanted in a bone defect, what effect would that have? How does a conventionally reamed defect compare with one which has been prepared with suction/irrigation in terms of early strength and stiffness? Would a clinician be able to discern a difference between these techniques using conventional radiological monitoring? We have attempted to address these concerns in this study.

It has been suggested that reaming a fractured bone has a coincidental benefit of autografting. ${ }^{13}$ However, after decades of reamed intramedullary procedures there is little proof that detritus is actually distributed into the fracture through the mechanical event of reaming. Frölke et $\mathrm{al}^{14}$ investigated whether or not reamings could deposit into a bone void in sheep cadavers. They created a semicircular defect $5 \mathrm{~mm}$ in length at the mid-shaft of the femur and orientated the study bone to use a possible gravitational effect. By using these arrangements to facilitate deposition they were able to accumulate reamings of $0.99 \mathrm{gm}$ (SD 0.12) in the gap. Because it took a specially designed and placed gap to acquire a gram of reamings, it seems unlikely that in clinical practice, where many inherent variables are encountered, reaming causes much autograft. Each reamer head extracted from the canal with compacted bone provides visual evidence of what a poor technique this would be for transporting graft to the site of a fracture or nonunion.

Do reamings actually initiate fracture healing? Here again, the evidence is elusive. Schemitsch et al, ${ }^{15}$ using a model of a fractured tibia of a sheep, found no difference between reamed and unreamed nails in the amount of new bone formation at 2,6 , or 12 weeks. They concluded that: "neither reamed nor unreamed nail insertion has an advantage with respect to the amount of new bone formation that occurs".

This study compared two reaming methods; one that is presumed to deposit autograft, and another that is expected to remove any graft produced. The results showed no significant difference in the volume of callus or in early strength and stiffness. However, the final quantitative and qualitative values favoured reaming with suction irrigation. There was more total callus in the RIA group (group A, $1426 \mathrm{~mm}^{2}$; group B, $1042 \mathrm{~mm}^{2}$ ) than in the conventionally reamed animals (group C, $405 \mathrm{~mm}^{2}$ ). The animals prepared with RIA also had stiffer bone $\left(0.48 \mathrm{Nm} /{ }^{\circ}\right)$ than those on whom a standard reamer was used $\left(0.31 \mathrm{Nm} /{ }^{\circ}\right)$, and it was comparatively stronger, at $6.94 \mathrm{Nm}$ for RIA and 5.21 Nm for Synream. 
What might account for the better results with the suction irrigation group? In all groups, the intramedullary vessels are destroyed by reaming, but conventional reaming produces a concentric necrosis of the inner cortical layers. ${ }^{16}$ This can be significantly reduced by a system that permits intra-operative irrigation and aspiration. ${ }^{17}$ Stürmer ${ }^{17}$ noted more viable bone in his group treated with suction irrigation, and it is reasonable to expect that a greater amount of live bone would be stronger than dead bone. Klein, ${ }^{18}$ in a histological assessment of bone from an in vivo RIA study, found that the bone was not infarcted by fat, as occurs with standard reamers and unreamed nails.

What are the reasons for the differences between the autofilled and the surgically-filled groups? The results from groups $\mathrm{A}$ and $\mathrm{C}$ indicate that the amount of reamed material deposited into the defect is questionable. However, in group B, captured bone particles were surgically placed into the bone void. The osteogenicity of the reamings is not in dispute. There are numerous studies showing the regenerative quality of the products of reaming. The early observations of Zucman, Maurer and Berbesson, ${ }^{19}$ Alfred et $\mathrm{al}^{20}$ and Tydings et $\mathrm{al}^{21}$ have been supplemented by later studies ${ }^{22-25}$ which have established the biological potential of this material. Schmidmaier et $\mathrm{al}^{26}$ in a human study found that the reamings from the intramedullary canal with the RIA had five of seven growth factors in higher concentrations (fibro growth factor (FGF) $\alpha$, platelet-derived growth factor (PDGF), Insulin-like growth factor (IGF)-I, transforming growth factor (TGF)- $\beta 1$ and bone morphogenic protein (BMP)-2) compared with curettings from the iliac crest. They also noted over twice as much protein in the RIA graft relative to the crest graft (38.8 $\mathrm{mg} / \mathrm{g}$ (SD 41.2) debris and $18.3 \mathrm{mg} / \mathrm{g}$ (SD 4.8) iliac crest). The increased protein density may a result of the RIA graft mass becoming its own filter as it clogs with marrow stroma being drawn through it by a vacuum.

Frölke et $\mathrm{al}^{27}$ have shown that reamings can stimulate the generation of callus in a distraction defect in the tibia of sheep. However, accomplishment of this required physical transfer of the reamings from the femur to the tibia and did not simulate an intramedullary reaming in preparation for stabilising a bone defect.

The present study indicates that the use of the RIA is clinically practicable and that targeted delivery of reamings could improve fracture healing. Conventional reaming scatters the bone particles indiscriminately throughout the intramedullary canal and only serendipitously in the region of the defect. Thus, deposition if it happens is not focal but generalised and accumulation of reamed particles is not certain to occur where it is most needed. However, direct surgical replantation of reamings into a bone void can substantially improve the volume stiffness and strength of callus during the early phase of healing.

No benefits in any form have been received or will be received from a commercial party related directly or indirectly to the subject of this article.

\section{References}

1. Küntscher G. Die Marknagelung. Berlin: Dr. Werner Springer Verlag, 1950:77-95.

2. Danckwardt-Lillieström G, et al. Intramedullary nailing after reaming: an investigation on the healing process in osteotomized rabbit tibias. Acta Orthop Scand 1970;134(Suppl):1-78.

3. Stürmer KM. Measurement of intramedullary pressure in an animal experiment and propositions to reduce the pressure increase. Injury 1993;24(Suppl 3):7-21.

4. Pape HC, Dwenger A, Regel G, et al. Pulmonary damage after intramedullary femoral nailing in traumatized sheep: is there an effect from different nailing methods? $J$ Trauma 1992;33:574-81.

5. Pape HC, Dwenger A, Regel G, et al. Influence of different methods of intramedullary femoral nailing on lung function in patients with multiple trauma. J Trauma 1993;35:709-16.

6. Buttaro M, Mocetti E, Alfie V, Paniego G, Pineiro L. Fat embolism and related effects during reamed and unreamed intramedullary nailing in a pig model. J Orthop Trauma 2002;16:239-44.

7. Coles RE, Clements FM, Lardenoye JW, et al. Transesophageal echocardiography in quantification of emboli during femoral nailing: reamed versus unreamed techniques. J South Orthop Assoc 2000;9:98-104.

8. Kröpfl A, Berger U, Redl H, Schlag G, Hertz H. Pulmonary response in hypovolemic shock, lung contusion and femoral fracture fixation. Shock 1999;12(Suppl 1):49.

9. Tornetta P III, Tiburzi D. Reamed versus nonreamed anterograde femoral nailing. J Orthop Trauma 2000;14:15-19.

10. Küntscher G. On the problem of infection after widening of the medullary cavity. Chirurgie 1968;39:236-40 (in German).

11. Danckwardt-Lilliestroem G, Lorenzi L, Olerud S. Intracortical circulation after intramedullary reaming with reduction of pressure in the medullary cavity. J Bone Joint Surg [Am] 1970;52-A:1390.

12. Stürmer KM, Schuchardt W. New aspects of closed intramedullary nailing and marrow cavity remaining in animal experiments: intramedullary pressure in marrow cavity reaming. Unfallheilkunde 1980;83:346-52 (in German).

13. Clatworthy MG, eClark DJ, Gray DH, Hardy AE. Reamed versus unreamed femoral nails: a randomized prospective trial. J Bone Joint Surg [Br] 1998;80-B:485-9.

14. Frölke JP, Van de Krol H, Bakker FC, Patka P, Haarman HJ. Destination of debris during intramedullary reaming: an experimental study on sheep femurs. Acta Orthop Belg 2000;66:337-40.

15. Schemitsch EH, Turchin DC, Kawalski MJ, Swiontkowski MF. Quantitative assessment of bone injury and repair after reamed and unreamed locked intramedullary nailing. J Trauma 1998;45:250-5.

16. Danckwardt-Lilliestroem G. Reaming of the medullary cavity and its effect on diaphyseal bone: a fluorochromic, microangiographic and histologic study on the rabbit tibia and dog femur. Acta Orthop Scand 1969;128:1-153.

17. Stürmer KM, Tammen ET. Verminderung der corticalen gefassschädigung durch kontinuierliches spülen and absaugen während des aufbohrens der markhöhle. Hefte zur unfallheilkunde. 1986;181:236 (in German).

18. Klein C. Der einflub von spülen und absaugen auf die biologiche reaktion nach markraumbohrung. Doctoral dissertation Freiburg, Germany 2006 (in German).

19. Zucman J, Maurer P, Berbesson C. Experimental study of osteogenic action of periosteal grafts, bone marow grafts, and centro-medullary riming. Rev Chir Orthop Reparatrice Appar Mot 1968;54:221-38 (in French).

20. Alfred $\mathbf{R}$, et al. Intramedullary bone reamings augmenting fracture fixation. American College of Surgeons Surgical Forum San Francisco 1984;35:523-5.

21. Tydings JD, Martino LJ, Kircher M, Alfred R, Lozman J. The osteoinductive potential of intramedullary canal bone reamings. Curr Surg 1986;43:121-4.

22. Furlong AJ, Giannoudis PV, Smith RM. Heterotopic ossification: a comparison between reamed and unreamed femoral nailing. Injury 1997;28:9-14.

23. Kessler SB, Rahn BA, Schweiberer L, Perren SM. Revascularization of intermediary fragments following interlocking nailing. Hefte Unfallheilkunde 1983;161:38-41 (in German).

24. Hogel F, Mueller CA, Peter R, Pfister U, Suedkamp NP. Bone debris: dead matter or vital osteoblasts. J Trauma 2004;56:363-7.

25. Wenisch S, Trinkaus K, Hild A, et al. Human reaming debris: a source of multipotent stem cells. Bone 2005;36:74-83.

26. Schmidmaier G, Herrmann S, Green J, et al. Quantitiative assessment of growth factors in reaming aspirate, iliac crest, and platelet preparation. Bone 2006;39:1156-63.

27. Frölke JP, Bakker FC, Patka P, Haarman HJ. Reaming debris in osteotomized sheep tibiae. J Trauma 2001;50:65-70. 